\title{
Creutzfeldt Jacob's Disease: A Senegalese Observation
}

\author{
Ahmadou Bamba Mbodji ${ }^{1}$, Alassane Mamadou Diop ${ }^{2}$, Momo Banda Ndiaye ${ }^{1}$, \\ Serigne Saliou Mbacke1, Khalifa Ababacar Mbaye1, Rokhaya Diagne1, Ibrahima Niang3, \\ Ndiaga Matar Gaye ${ }^{1}$, Maouly Fall², Adjaratou Sow ${ }^{1}$, Anna Basse1, Lala Bouna Seck ${ }^{1}$, \\ Moustapha Ndiaye ${ }^{1}$, Amadou Gallo Diop ${ }^{1}$
}

\author{
${ }^{1}$ Department of Ibrahima Pierre Ndiaye Neuroscience, Fann Hospital, Dakar, Sénégal \\ ${ }^{2}$ Department of Neurology, Pikine Hospital, Dakar, Sénégal \\ ${ }^{3}$ Department of Radiology, Fann Hospital, Dakar, Sénégal \\ Email: *modjahmadoubamba@yahoo.fr
}

How to cite this paper: Mbodji, A.B., Diop, A.M., Ndiaye, M.B., Mbacke, S.S., Mbaye, K.A., Diagne, R., Niang, I., Gaye, N.M., Fall, M., Sow, A., Basse, A., Seck, L.B., Ndiaye, M. and Diop, A.G. (2022) Creutzfeldt Jacob's Disease: A Senegalese Observation. Neuroscience \& Medicine, 13, 43-48.

https://doi.org/10.4236/nm.2022.131003

Received: October 23, 2021

Accepted: March 4, 2022

Published: March 7, 2022

Copyright $\odot 2022$ by author(s) and Scientific Research Publishing Inc. This work is licensed under the Creative Commons Attribution International License (CC BY 4.0).

http://creativecommons.org/licenses/by/4.0/

\begin{abstract}
Creuzfelt-Jakob Disease is a rare and progressive neurodegenerative disease that results in fatal, transmissible, subacute, spongiform encephalopathy characterized by rapidly progressive dementia and movement disorder. We present a 62-year-old male with no medical history who was admitted to our hospital because of gait and balance disturbance, language impairment and progressive motor deficit of the four limbs. A neurological examination found frontal lobe syndrome signs, myoclonic movements, pyramidal and extrapyramidal signs. Brain Magnetic Resonance Imaging detected high intensity areas in the basal ganglia. EEG showed generalized triphasic sharp-wave complexes. A Cerebro Spinal Fluid examination found protein 14-3-3. Death occurred six months after onset. This is the first known case of Creuzfelt-Jakob Disease documented in Senegal.
\end{abstract}

\section{Keywords}

Creutzfeldt-Jakob Disease, Protein 14-3-3, Prion Disease, Rapidly Progressive Dementia

\section{Introduction}

Creutzfeldt-Jakob disease (CJD) is the most common subacute, transmissible, spongiform encephalopathy. It is a neurodegenerative disease of the central nervous system caused by misfolded prion protein. It is fairly rare and can present in several forms: familial, infectious and sporadic [1]. The diagnosis is 
evoked upon clinical, electrical, biological and neuroradiological arguments but only pathology can confirm it [1]. Publications in Africa are relatively rare. We report the observation of a first documented case in Senegal.

\section{Observation}

The patient was a 62 years old retired mechanic with no medical history. He seeked medical attention for gait and balance disturbance, language impairment and progressive motor deficit. The history started in November 2019, with progressive ataxia not worsened by eyes' closing (negative Romberg's sign) and hypersomnia with excessive daytime sleepiness. He went to a hospital in the United States where he received treatment by Levetiracetam $500 \mathrm{mg}$ : 1 tablet, twice a day. A month later, in December 2019, behavioral changes started appearing with agitation, confusion and irritability; the patient also presented with visual and auditory hallucinations and dysarthria. The lack of clinical improvement motivated his return to Senegal where he resorted to traditional herbal medicine. In January 2020, the clinical picture worsened with akinetic mutism, dysphagia and progressive motor deficit of the 4 limbs, motivating his hospitalization in the neurology department. Neurological examination revealed spastic tetraparesis predominant in the lower limbs, bilateral myoclonic jerks predominant in the upper limbs, increase muscle tone with cogwheel rigidity and Babinski sign, frontal lobe syndrome with palmar grasp reflex, palmomental reflex and grabellar tap sign. Bloodwork found a non-specific inflammatory syndrome with predominant neutrophilic leukocytosis at 14.420 and a positive C-Reactive Protein (CRP) at 115. Retroviral serology and hepatitis B serology were negative, as well as the search of anti-onconeuronal antibody and anti-NMDA receptor antibody serun tests. The Cerebro Spinal Fluid (CSF) analysis was normal with proteins at $0.16 \mathrm{~g} / \mathrm{L}$, glucid at $0.91 \mathrm{~g} / \mathrm{L}$ and no white blood cells. Protein 14.3.3 dosage in the CSF was positive with normal neopterin rate. The rest of the workup was normal including ionogram, blood sugar, liver function, calcium, thyroid and parathyroid hormones. Brain Magnetic Resonance Imaging (MRI) showed bilateral and symmetrical hyper intensity in caudate and lenticular nuclei in T2 and FLAIR sequences and hypo intensity without enhancement by Gadolinium injection in T1 sequence (Figure 1 and Figure 2). Electro-Encephalography (EEG) showed a well-organized wakefulness pattern followed by drowsiness with generalized triphasic slow complexes of short periodicity ( 2 to 2.5 seconds) and bi-frontal predominance, without focal irritative abnormalities (Figure 3). The diagnosis of probable Creutzfeldt-Jakob disease was made according to the diagnostic criteria for sporadic CJD [2]. The family was informed of the diagnosis and the patient was discharged. The medical team agreed with the family on a treatment plan including visits to the neurology department every other week for evaluation and treatment updates. A nurse was affiliated to the patient for daily needs such as suction, feeding through nasogastric tube, physical therapy and drug (oral and intraveinous) administration. Death occurred after six months 
evolution in an infectious context with multiple pressure ulcers. The patient presented with anemia, urinary tract infection, pulmonary infection, denutrition and stage 4 pressure ulcers in the buttock.

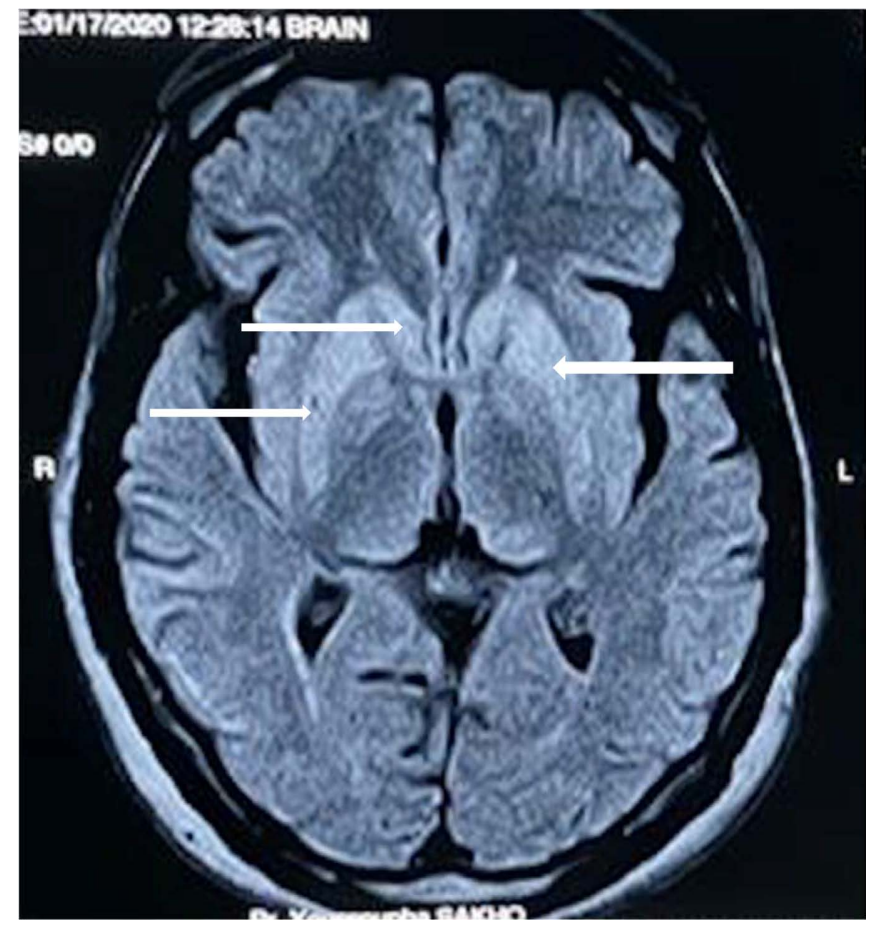

Figure 1. Bilateral and symmetrical hyperintensity in caudate and lenticular nuclei in FLAIR sequence MRI (white arrows).

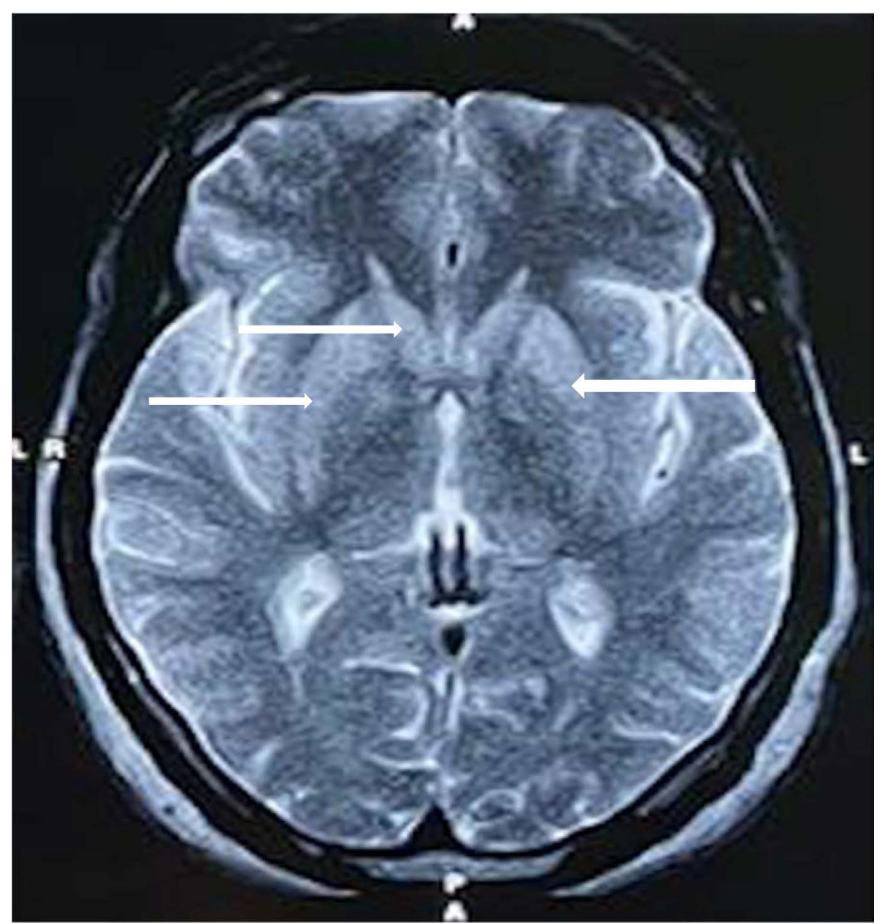

Figure 2. Bilateral and symmetrical hyperintensity in caudate and lenticular nuclei in T2 sequence MRI (white arrows). 
FP2 F4 mom FACA

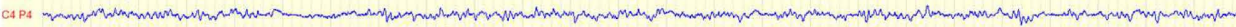

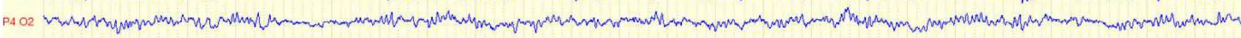

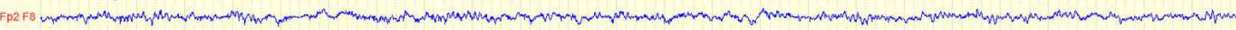

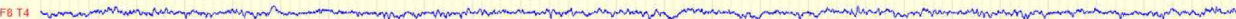

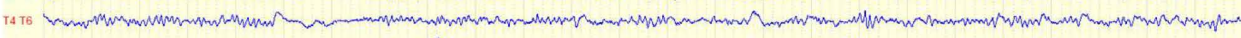
T6 02 Ansmm

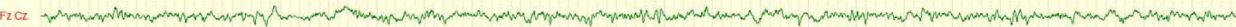

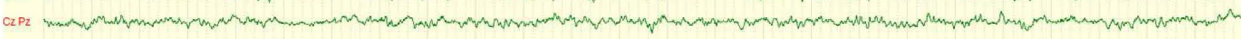
FP1 F3 3. F3 3 3 C9 $P_{3}$ C.

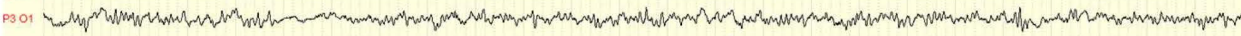
FP 177 C

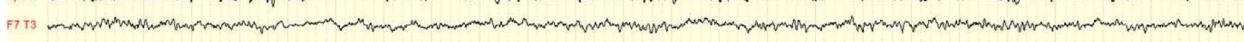
TS T5 -

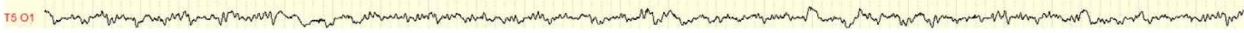

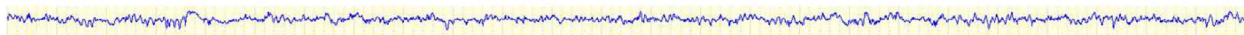
.

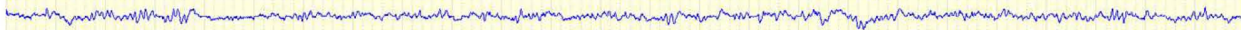

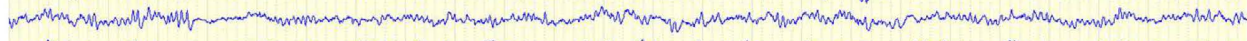
Non

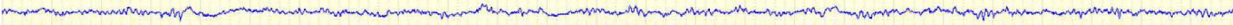

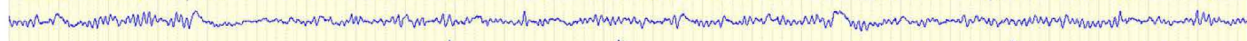

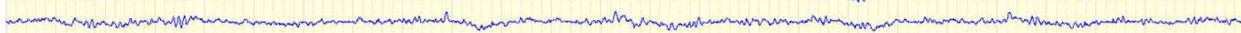

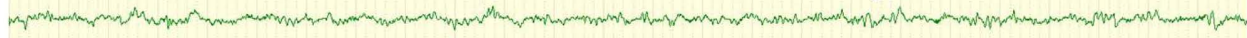
.

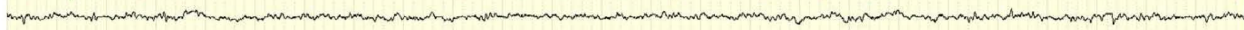

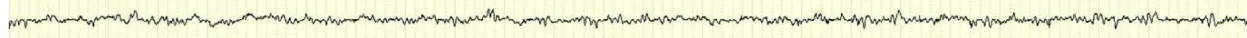

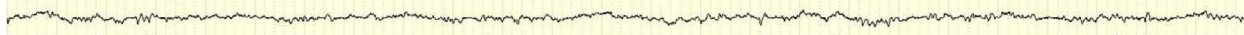

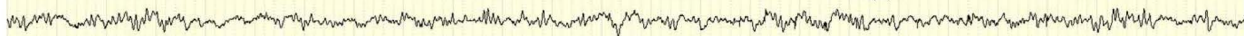

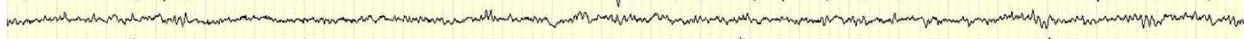

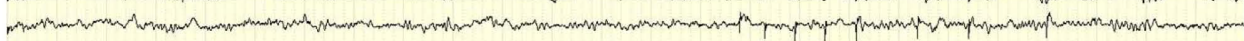
monm

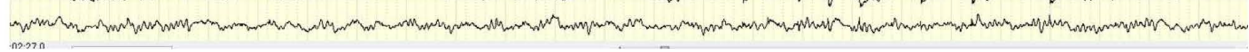

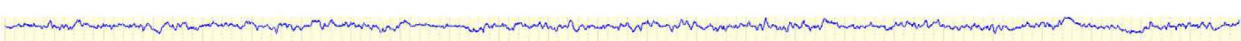
(1) C.

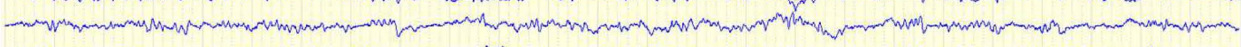
com Com C.m.

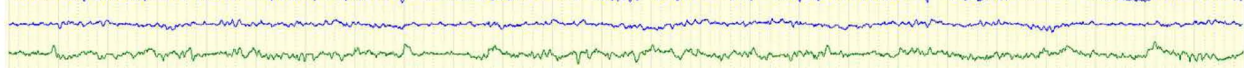
C.m Com crman

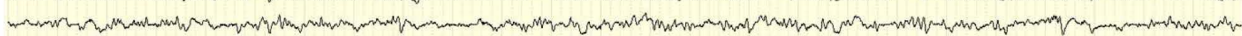
com (n)

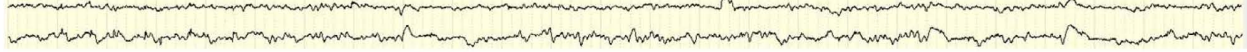

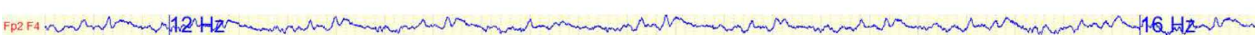
$C_{4} P_{4} A C A$ $P_{4} \mathrm{P}_{4} \mathrm{C}$ a FP2 $F 8$ OW

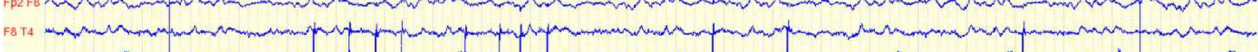

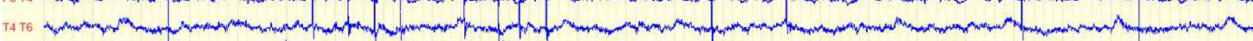

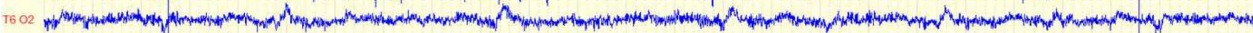

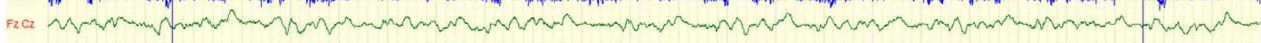
$C_{2} P_{2}$ M M FP1F3 F3с3

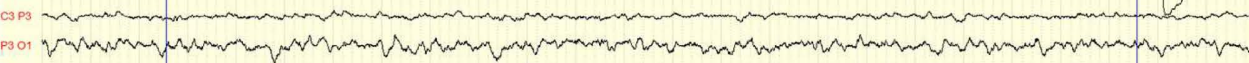
P301 VP1 77 C

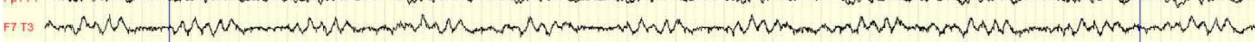
Tо T5

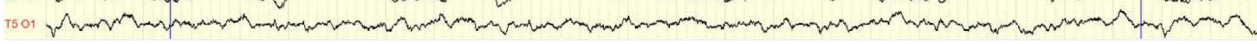

Figure 3. Generalized triphasic sharp-wave complexes. 


\section{Discussion}

Creutzfeldt-Jakob disease is very rare and can present in various forms: sporadic, familial or infectious (most often iatrogenic or linked to cattle exposure) [1]. It is described worldwide in countries with an efficient epidemiological surveillance system, but African publications on the subject are rare [3]. It occurs mostly after 65 , matching to onset age in our patient.

Neurological involvement is at the forefront of clinical picture in our patient with cerebellar ataxia. This onset mode is found in $34 \%$ of cases [4].

Chronic encephalopathy as presented by our patient lacks specificity. It has been reported in the literature with variable frequency from $74 \%$ to $97 \%$ [5].

The MRI revealed in our patient bilateral and symmetrical hyperintensity signal in T2 sequence, located in the basal ganglia, more precisely at the head of the caudate nucleus and in the lenticular nucleus. This MRI aspect is compatible with literature data in which signal abnormalities are more frequent in the basal ganglia and/or the gray matter bundles in T2, FLAIR and diffusion sequences: the latter being the most sensitive for early diagnosis. It should be noted that toxic encephalopathy or mitochondrial cytopathy may give similar MRI aspects [6]. The exact mechanism leading to signal abnormalities in the basal ganglia remains unknown, although it was recently reported that the presence of neuropathologically detectable prion proteins could match the images found on MRI [7]. EEG shows periodic or pseudo periodic sharp waves complexes (PSWC) that can be simple, biphasic or triphasic. Its importance is such that the absence of electrical abnormalities should not lead to diagnosis rejection but rather the repetition of EEGs in the event of strong clinical suspicion because these abnormalities may only be transient. This was the case in our patient in whom the first EEG showed a slow, low volted tracing while the second, realized three weeks later, revealed slow generalized triple-phase complexes with short periodicity ( 2 to 2.5 seconds) with maximum distribution in the frontal area, without focal irritative abnormalities. Its' sensitivity is evaluated at $67 \%$ with $91 \%$ specificity [8].

It should be noted that these aspects are however not specific and can be observed during toxic and metabolic encephalopathies, but the clinical and neuroradiological context helps in the diagnosis [9]. The protein P 14-3-3 dosage is, to date, the only recognized biological marker for diagnosis. It allows going from a "possible" stage to a "probable" stage with sensitivity greater than $97 \%$ and specificity between $70 \%$ and $96 \%$ for the sporadic form [10]. The positivity of this protein in our patient was an additional argument for diagnosing the disease according to the criteria of EuroCJD 2017 [2].

\section{Conclusion}

Even though Creutzfeldt-Jakob disease is rare, it is well underdiagnosed in our regions. It should be a differential diagnosis in chronic encephalopathy among the elderly. Biological, electroencephalographic and neuroradiological arguments help assess the diagnosis. 


\section{Ethics}

Informed consent was obtained from the patient's family to report this case.

\section{Authors' Contribution}

All authors have contributed to this work in a manner that meets the criteria for authorship of the ICMJE. All authors have read and approved the final version of the manuscript.

\section{Conflicts of Interest}

The authors declare no conflicts of interest regarding the publication of this paper.

\section{References}

[1] Brandel, J.-P. and Haik, S. (2009) Maladies à prions ou encéphalopathies spongiformes transmissibles. EMC-Neurologie, 6, 1-22. https://doi.org/10.1016/S0246-0378(09)43811-9

[2] Creutzfeldt-Jakob Disease International Surveillance Network (2018) CJD Surveillance Data 1993-2018. https://www.eurocjd.ed.ac.uk/node/833

[3] Aka-diarra, E., Sonan-douayoua, T., Asssi, B., Kouame-Assouan, A.-E., Doumbia, M., Datie, A.-M., Yapo, B.F. and Kouassi, E.B. (2007) Interêt de l'electroencephalogramme (eeg) dans le diagnostic de la maladie de creutzfeldt-jakob (mcj) en Afrique: description de trois cas en cote d'ivoire. African Journal of Neurological Sciences, 26, 66-72. https://doi.org/10.4314/ajns.v26i2.7600

[4] Beauvais, P. and Billette de Villemeur, T. (1999) Maladies à prion ou encéphalopathies spongiformes transmissibles. In: Encyclopédie Médico-Chirurgicale, Elsevie, Paris, $16 \mathrm{p}$.

[5] Zerr, I., et al. (2000) Current Clinical Diagnosis in Creutzfeldt-Jakob Disease: Identification of Uncommon Variants. Annals of Neurology, 48, 323-329. https://doi.org/10.1002/1531-8249(200009)48:3<323::AID-ANA6>3.0.CO;2-5

[6] Shiga, Y., Miyazawa, K., Sato, S., Fukushima, R., Shibuya, S., Sato, Y., et al. (2004) Diffusion-Weighted MRI Abnormalities as an early Diagnostic Marker for Creutzfeldt-Jakob Disease. Neurology, 63, 443-449. https://doi.org/10.1212/01.WNL.0000134555.59460.5D

[7] Haik, S., Dormont, D., Faucheux, B.A., Marsault, C. and Hauw, J.J. (2002) Prion protein Deposits Match Magnetic Resonance Imaging Signal Abnormalities in CreutzfeldtJakob Disease. Annals of Neurology, 51, 797-799. https://doi.org/10.1002/ana.10195

[8] Steinhoff, B.J., Racker, S., Herrendorf, G., Poser, S., Grosche, S., Zerr, I., Kretzschmar, H. and Weber, T. (1996) Accuracy and Reliability of Periodic Sharp Complexes in Creutzfeldl-Jakob Disease. Archives of Neurology, 53, 162-166. https://doi.org/10.1001/archneur.1996.00550020074017

[9] Wang, L.H., Bucelli, R.C., Patrick, E., Rajderkar, D., Alvarez III, E., Lim, M.M., et al. (2013) Role of Magnetic Resonance Imaging, Cerebrospinal Fluid, and Electroencephalogram in Diagnosis of Sporadic Creutzfeldt-Jakob Disease. Journal of Neurology, 260, 498-506. https://doi.org/10.1007/s00415-012-6664-6

[10] Emile, C. (2019) Marqueurs biologiques des maladies neurodégénératives. Option/ Bio, 30, 26-28. https://doi.org/10.1016/S0992-5945(19)30008-X 